\title{
Supercritical Carbon Dioxide Drying of Methanol-Zinc Borate Mixtures
}

\author{
Mehmet Gönen, ${ }^{*}{ }^{\dagger}$ Devrim Balköse ${ }^{\dagger}$ Ram B. Gupta, ${ }^{\dagger}$ and Semra Ülkü ${ }^{\dagger}$ \\ Department of Chemical Engineering, Izmir Institute of Technology, Gülbahçe Köyü, \\ Urla, Izmir 35430, Turkey, and Department of Chemical Engineering, Auburn University, \\ Auburn, Alabama 36849-5127
}

\begin{abstract}
Supercritical carbon dioxide $\left(\mathrm{CO}_{2}\right)$ drying of zinc borate species was investigated to evaluate possible chemical alterations in the product during the drying. Methanol-wetted zinc borates produced either from borax decahydrate and zinc nitrate hexahydrate $\left(2 \mathrm{ZnO} \cdot 3 \mathrm{~B}_{2} \mathrm{O}_{3} \cdot 7 \mathrm{H}_{2} \mathrm{O}\right)$ or from zinc oxide and boric acid $\left(2 \mathrm{ZnO} \cdot 3 \mathrm{~B}_{2} \mathrm{O}_{3} \cdot 3 \mathrm{H}_{2} \mathrm{O}\right)$ were dried by both conventional and supercritical carbon dioxide drying methods. Zinc borate samples dried by both techniques were characterized using analytical titration, $\mathrm{X}$-ray powder diffraction (XRD), thermo gravimetric analysis (TGA), Fourier transform infrared (FTIR) spectroscopy, elemental analysis, and scanning electron microscopy (SEM). It was found that while zinc borate obtained from zinc oxide and boric acid did not have any chemical interaction with $\mathrm{CO}_{2}$, carbonates were formed on the surface of zinc borate obtained from borax decahydrate and zinc nitrate hexahydrate. The main factor for the carbonate formation during supercritical $\mathrm{CO}_{2}$ drying is anticipated as the structural differences of zinc borate species. $\mathrm{CO}_{2}$ is a nonpolar solvent, and it does not usually react with polar substances unless water is present in the medium. While $2 \mathrm{ZnO} \cdot 3 \mathrm{~B}_{2} \mathrm{O}_{3} \cdot 3 \mathrm{H}_{2} \mathrm{O}$ had three bound $\mathrm{OH}$ groups, $2 \mathrm{ZnO} \cdot 3 \mathrm{~B}_{2} \mathrm{O}_{3} \cdot 7 \mathrm{H}_{2} \mathrm{O}$ had five bound $\mathrm{OH}$ groups and one mole of water of crystallization. It is proposed that the water of crystallization reacts with $\mathrm{CO}_{2}$ forming carbonic acid. Then, carbonic acid, which is stronger than boric acid, substitutes borate ions from their zinc salts.
\end{abstract}

\section{Introduction}

Zinc borate is an important inorganic hydrated borate that finds applications ranging from polymers to paints for various purposes, such as flame retardant, corrosion inhibitor, etc. ${ }^{1}$ depending on the type of zinc borate. Zinc borates function not only as flame retardant but also as smoke suppressant, afterglow suppressant, and antitracking agent for both halogen-containing and halogen-free polymers. The recent developments in this area were reviewed by Shen and co-workers. ${ }^{2}$ Zinc borates are also used as heat stabilizer for polyvinyl chloride (PVC). Mixtures of zinc borate and zinc phosphate showed a synergistic effect on retarding dehydrochlorination of PVC. ${ }^{3}$ They neutralize the hydrogen chloride eliminated by dehydrochlorination and prevent autocatalytic effect of hydrogen chloride on thermal degradation.

Since boron atoms can coordinate to three $\left(\mathrm{BO}_{3}\right)$ and four $\left(\mathrm{BO}_{4}\right)$ oxygen atoms, it enables the formation of a substantial number of chemical structures. In addition to the monomeric structures in the units, borates occur in polymeric configurations, as well. Polymerization takes place by the elimination of water molecule from two hydroxyl $(\mathrm{OH})$ groups of borate units. Further polymerization of borates forms sheet or network line structures. The most of the natural borates contain water of crystallization; but the synthetically produced borates can be formulated to contain hydroxyl groups instead of bound water or vice versa. For example, ${ }^{1}$ zinc borate with a formula of $2 \mathrm{ZnO} \cdot 3 \mathrm{~B}_{2} \mathrm{O}_{3} \cdot 3 \mathrm{H}_{2} \mathrm{O}$ has $(\mathrm{OH})$ groups in its structure $\left(\mathrm{Zn}\left[\mathrm{B}_{3} \mathrm{O}_{4}(\mathrm{OH})_{3}\right]\right)$, on the other hand, zinc borate with an oxide formula of $2 \mathrm{ZnO} \cdot 3 \mathrm{~B}_{2} \mathrm{O}_{3} \cdot 7 \mathrm{H}_{2} \mathrm{O}$ has both $(\mathrm{OH})$ groups and water of crystallization as $\mathrm{Zn}\left[\mathrm{B}_{3} \mathrm{O}_{3}(\mathrm{OH})_{5}\right] \cdot \mathrm{H}_{2} \mathrm{O}$ in its structure according to the IR analysis.

* To whom correspondence should be addressed. E-mail: gonen19@ gmail.com.

Izmir Institute of Technology.

* Auburn University.
There are several types of zinc borates $\left(4 \mathrm{ZnO} \cdot \mathrm{B}_{2} \mathrm{O}_{3} \cdot \mathrm{H}_{2} \mathrm{O}\right.$, $\mathrm{ZnO} \cdot \mathrm{B}_{2} \mathrm{O}_{3} \cdot \sim 1.12 \mathrm{H}_{2} \mathrm{O}, \quad \mathrm{ZnO} \cdot \mathrm{B}_{2} \mathrm{O}_{3} \cdot \sim 2 \mathrm{H}_{2} \mathrm{O}, \quad 6 \mathrm{ZnO} \cdot 5 \mathrm{~B}_{2} \mathrm{O}_{3} \cdot$ $3 \mathrm{H}_{2} \mathrm{O}, 2 \mathrm{ZnO} \cdot 3 \mathrm{~B}_{2} \mathrm{O}_{3} \cdot 7 \mathrm{H}_{2} \mathrm{O}, 2 \mathrm{ZnO} \cdot 3 \mathrm{~B}_{2} \mathrm{O}_{3} \cdot 3 \mathrm{H}_{2} \mathrm{O}, 3 \mathrm{ZnO} \cdot 5 \mathrm{~B}_{2} \mathrm{O}_{3} \cdot$ $14 \mathrm{H}_{2} \mathrm{O}, \mathrm{ZnO} \cdot 5 \mathrm{~B}_{2} \mathrm{O}_{3} \cdot 4.5 \mathrm{H}_{2} \mathrm{O}$ ) that have been developed since 1940 s. Only $4 \mathrm{ZnO} \cdot \mathrm{B}_{2} \mathrm{O}_{3} \cdot \mathrm{H}_{2} \mathrm{O}$ and $2 \mathrm{ZnO} \cdot 3 \mathrm{~B}_{2} \mathrm{O}_{3} \cdot 3 \mathrm{H}_{2} \mathrm{O}$ are preferred in polymers that require high processing temperature, as they have high dehydration temperatures of 410 and $290{ }^{\circ} \mathrm{C}$, respectively. ${ }^{4}$ On the other hand, $2 \mathrm{ZnO} \cdot 3 \mathrm{~B}_{2} \mathrm{O}_{3} \cdot 7 \mathrm{H}_{2} \mathrm{O}$ releases its water at about $200{ }^{\circ} \mathrm{C}$ and it is used as a lubricating additive or flame retardant where low processing temperature is needed. For instance, $2 \mathrm{ZnO} \cdot 3 \mathrm{~B}_{2} \mathrm{O}_{3} \cdot 7 \mathrm{H}_{2} \mathrm{O}$ and $2 \mathrm{ZnO} \cdot 3 \mathrm{~B}_{2} \mathrm{O}_{3} \cdot 3 \mathrm{H}_{2} \mathrm{O}$ are used to provide flame retardancy for polyethylene and polypropylene, respectively, since they are stable at the processing temperatures of polyethylene $\left(120-150{ }^{\circ} \mathrm{C}\right)$ and polypropylene $\left(160-200{ }^{\circ} \mathrm{C}\right)$. In case of fire, both of them will function as flame retardant by releasing $\mathrm{H}_{2} \mathrm{O}$ and forming a glass film. While $2 \mathrm{ZnO} \cdot 3 \mathrm{~B}_{2} \mathrm{O}_{3} \cdot 7 \mathrm{H}_{2} \mathrm{O}$ is produced from borax decahydrate and zinc salt at below about $70{ }^{\circ} \mathrm{C}, 2 \mathrm{ZnO} \cdot 3 \mathrm{~B}_{2} \mathrm{O}_{3} \cdot 3 \mathrm{H}_{2} \mathrm{O}$ is produced commercially by the reaction of zinc oxide with boric acid at $90{ }^{\circ} \mathrm{C} .{ }^{5} 2 \mathrm{ZnO} \cdot 3 \mathrm{~B}_{2} \mathrm{O}_{3} \cdot 7 \mathrm{H}_{2} \mathrm{O}$ consumes less energy during its production than $2 \mathrm{ZnO} \cdot 3 \mathrm{~B}_{2} \mathrm{O}_{3} \cdot 3 \mathrm{H}_{2} \mathrm{O}$ since it is produced at a lower temperature. If processing conditions allow, it is more economical to use $2 \mathrm{ZnO} \cdot 3 \mathrm{~B}_{2} \mathrm{O}_{3} \cdot 7 \mathrm{H}_{2} \mathrm{O}$.

There have been a number of recent studies for zinc borate production. For example, Shi et al. produced $2 \mathrm{ZnO} \cdot 3 \mathrm{~B}_{2} \mathrm{O}_{3}$. $3 \mathrm{H}_{2} \mathrm{O}$ by a rheological phase reaction method using zinc oxide and boric acid. ${ }^{6}$ As this technique utilized a small amount of water in the reaction, it did not produce an aqueous waste stream that needs to be treated. ${ }^{6}$ But the large particles (about $19 \mu \mathrm{m}$ in diameter) obtained were unsuitable for many applications. The synthesis of $4 \mathrm{ZnO} \cdot \mathrm{B}_{2} \mathrm{O}_{3} \cdot \mathrm{H}_{2} \mathrm{O}$ with different morphologies was studied using borax decahydrate and zinc sulfate hexahydrate in a surfactant assisted hydrothermal reaction method. ${ }^{7}$ The influence of hydrothermal reaction parameters, such as initial $\mathrm{pH}$, temperature, time, and raw materials' concentrations were investigated. The optimal initial $\mathrm{pH}$ range was pointed 


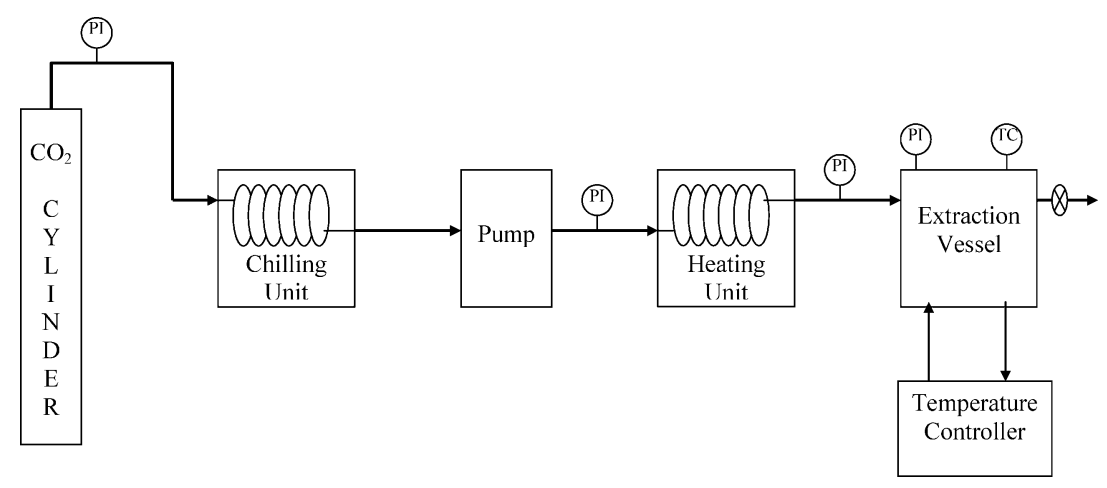

Figure 1. Schematic representation of supercritical $\mathrm{CO}_{2}$ drying system.

out as 8-9 and at $\mathrm{pH}$ values of 3,6 , and 10 no product formation was reported. The reaction temperature between 90 and $180{ }^{\circ} \mathrm{C}$ was stated as adequate for the synthesis of $4 \mathrm{ZnO} \cdot \mathrm{B}_{2} \mathrm{O}_{3} \cdot \mathrm{H}_{2} \mathrm{O}$ crystals. The reaction time was also examined based on the morphological changes of product and increasing reaction time caused random orientation of produced nanorods. ${ }^{7}$ However, thermal behavior of produced zinc borate samples was not investigated.

The number of studies in nanosized zinc borate production has increased substantially due to many potential applications. ${ }^{8,9}$ For instance, Tian and co-workers produced zinc borate nanodiscs from borax and zinc sulfate in the presence of oleic acid as a modifying agent. ${ }^{9}$ The produced nanodiscs were used as lubricating oil additive and they decreased friction coefficient value from 0.12 to 0.02 . Nanoparticles agglomerate owing to the influence of interfacial tension during conventional drying. ${ }^{10}$ Supercritical fluid drying where the solvent is removed above its critical temperature $\left(T_{\mathrm{c}}\right)$ and critical pressure $\left(P_{\mathrm{c}}\right)$ is suggested to overcome the agglomeration and sticking of nanoparticles. In other words, since the liquid-vapor interface and capillary pressure are eliminated in supercritical fluid drying, particles do not tend to gather. Supercritical fluids have been used in areas ranging from natural products extraction, materials cleaning, chemical reactions, nanoparticle preparation and drying. ${ }^{11,12}$ The production of nanosized metal borates was studied using supercritical ethanol drying and supercritical $\mathrm{CO}_{2}$ drying. ${ }^{13,14}$ Supercritical $\mathrm{CO}_{2}$ drying has been utilized in many applications owing to the fact that carbon dioxide is inexpensive, environmentally benign, not flammable, nontoxic and can be regenerated easily by a cycle system. The preparation of nanometer copper borate with supercritical carbon dioxide drying was studied by $\mathrm{Hu}$ and co-workers. ${ }^{15}$ In those studies, supercritical $\mathrm{CO}_{2}$ drying was preferred to prevent the agglomeration of metal borate particles. However, there are some ambiguities, such as the interaction between copper borate and supercritical $\mathrm{CO}_{2}$ not being taken into account and the thermal behavior of copper borate not being examined considering the above phenomenon.

To prevent agglomeration of wet zinc borate particles filtered from aqueous medium during drying, water was replaced with methanol by washing and filtering the particles with methanol. Methanol is a solvent having a lower surface tension (22.1 $\mathrm{mN} / \mathrm{m})$ than that of water $(72.0 \mathrm{mN} / \mathrm{m})$ and it is miscible in all proportions with supercritical carbon dioxide. During supercritical carbon dioxide drying, methanol was extracted from zinc borate particles by supercritical carbon dioxide in a flowing system. It was expected that the particles would not stick to each other since there is no liquid surface tension attracting them. Even if no interaction of carbon dioxide with zinc borate was expected based on previous publications, ${ }^{15}$ interactions were observed in this study. This paper aims to elucidate the interactions between zinc borate species and supercritical carbon dioxide. For this purpose, zinc borates produced from "borax decahydrate and zinc nitrate hexahydrate" and "boric acid and zinc oxide" pairs were dried both by conventional and supercritical $\mathrm{CO}_{2}$ techniques, and the samples were characterized before and after drying by using X-ray diffraction, FTIR spectroscopy, TGA, elemental analysis and scanning electron microscopy.

\section{Experimental Details}

2.1. Materials. Sodium borate decahydrate (99.5-105.0\%), zinc oxide (99.9\%), and boric acid $(99.99 \%)$ from SigmaAldrich, and zinc nitrate hexahydrate $(99.9 \%)$ from Fluka were used in the production of zinc borate species. D-Mannitol and EDTA from Sigma-Aldrich were used in the determination of $\mathrm{B}_{2} \mathrm{O}_{3}$ and zinc contents in zinc borates. Deionized water from Milli-Q purification system and methanol (99.9\%) from SigmaAldrich were used in experiments. $\mathrm{CO}_{2}(99.9 \%)$ was obtained from Air Gas Company.

2.2. Synthesis of Zinc Borates. Zinc borate species were produced by using two different raw material pairs. In the first, zinc borate $(\mathrm{ZnB}-1)$ was produced by using $50 \mathrm{~cm}^{3} 1 \mathrm{~mol} \cdot \mathrm{dm}^{-3}$ borax decahydrate and $50 \mathrm{~cm}^{3} 1 \mathrm{~mol} \cdot \mathrm{dm}^{-3}$ zinc nitrate hexahydrate at $70{ }^{\circ} \mathrm{C}$ for $5 \mathrm{~h}$ reaction time. ${ }^{9,13}$ In the latter, zinc borate $(\mathrm{ZnB}-2)$ was produced from $4.7 \mathrm{~mol} \cdot \mathrm{dm}^{-3}$ boric acid and stoichiometric amount of zinc oxide to adjust $\mathrm{B}_{2} \mathrm{O}_{3}$ / $\mathrm{ZnO}$ molar ratio $2.0^{16}$ at $90{ }^{\circ} \mathrm{C}$ for $5 \mathrm{~h}$ reaction time. Both reactions were carried out in a $250 \mathrm{~cm}^{3}$ glass bottle equipped with a magnetic stirrer and a temperature controller.

To remove the unreacted zinc nitrate hexahydrate and sodium borate decahydrate in the first method and unreacted boric acid in the second method, the prepared precipitates were washed using deionized water. Subsequently, zinc borates were washed three times with methanol to replace water. Zinc borate samples contained approximately $70 \%$ in mass methanol.

2.3. Drying of Zinc Borates Wetted with Methanol. Different portions of the samples were either conventionally dried in air circulating oven at $110^{\circ} \mathrm{C}$ until reaching a constant weight or by supercritical $\mathrm{CO}_{2}$ drying for different periods. The supercritical $\mathrm{CO}_{2}$ drying of zinc borate was performed in a supercritical $\mathrm{CO}_{2}$ extraction system as shown in Figure 1.

In supercritical $\mathrm{CO}_{2}$ drying, $4.0 \mathrm{~g}$ zinc borate sample (ZnB-1 or $\mathrm{ZnB}-2$, wetted with methanol) was first packaged in a filter paper pouch and then put into the $100 \mathrm{~cm}^{3}$ extraction autoclave. The autoclave was pressurized with $\mathrm{CO}_{2}$ up to $10 \mathrm{MPa}$ at 40 ${ }^{\circ} \mathrm{C}$ using a pump (Thar P-50). The temperature of extraction vessel was maintained at $40{ }^{\circ} \mathrm{C}$ by a temperature controller and a heating tape. Dynamic drying was performed at $10 \mathrm{MPa}$ with a $\mathrm{CO}_{2}$ flow rate of $2.5-3.0 \mathrm{~g} \cdot \mathrm{min}^{-1}$ for different drying times. 
Table 1. Composition of the Samples

\begin{tabular}{|c|c|c|c|c|c|c|c|c|c|}
\hline \multirow[b]{2}{*}{ sample } & \multirow[b]{2}{*}{ N\% } & \multirow[b]{2}{*}{$\mathrm{C} \%$} & \multicolumn{2}{|c|}{$\mathrm{CO}_{2} \%$} & \multirow[b]{2}{*}{$\mathrm{H} \%$} & \multicolumn{2}{|c|}{$\mathrm{H}_{2} \mathrm{O} \%$} & \multirow[b]{2}{*}{$\mathrm{B}_{2} \mathrm{O}_{3} / \mathrm{ZnO}$} & \multirow[b]{2}{*}{$\mathrm{ZnCO}_{3} \%$} \\
\hline & & & from $\mathrm{C} \%$ & from TGA & & from $\mathrm{H} \%$ & from TGA & & \\
\hline $\mathrm{ZnB}-1$ & 0.23 & 0.153 & 0.56 & & 2.52 & 22.68 & 23.01 & 1.35 & \\
\hline ZnB-1SC-2 & & 1.43 & 5.24 & 5.50 & 2.22 & 19.98 & 15.35 & & 15.67 \\
\hline $\mathrm{ZnB}-1 \mathrm{SC}-3$ & & 1.47 & 5.39 & 5.76 & 2.24 & 20.10 & 15.27 & & 16.41 \\
\hline $\mathrm{ZnB}-2$ & & & & & & & 13.31 & 1.5 & \\
\hline $\mathrm{ZnB}-2 \mathrm{SC}$ & & 0.26 & 0.95 & & 1.43 & 12.87 & 13.16 & 1.5 & \\
\hline
\end{tabular}

While ZnB-1 was dried for 2, 3, and 4 h periods; ZnB-2 was dried for $2 \mathrm{~h}$ only. These samples were called as $\mathrm{ZnB}-1 \mathrm{SC}-1$, ZnB-1SC-2, ZnB-1SC-3, and ZnB-2SC, respectively. Afterward, the autoclave was slowly depressurized to atmosphere at $40{ }^{\circ} \mathrm{C}$. Finally, supercritical $\mathrm{CO}_{2}$ dried zinc borate samples were obtained.

2.4. Characterization of Zinc Borates. Zinc borate samples were characterized using the following techniques before and after supercritical drying process. The crystalline structure and purity of the zinc borate samples were determined using X-ray powder diffractometer (Philips Xpert-Pro) with $\mathrm{Cu} \mathrm{K \alpha}$ radiation at $45 \mathrm{kV}$ and $40 \mathrm{~mA}$. The scattering data were collected in the $5-70^{\circ} 2 \theta$ range. Scanning electron microscopes, (SEM), (Philips XL30 SFEG and Zeiss DSM 940), were used for identification of particle size and morphology. The transmission spectra of $\mathrm{KBr}$ pellets prepared by mixing $4.0 \mathrm{mg}$ of zinc borate and $196 \mathrm{mg}$ of $\mathrm{KBr}$ in an agate mortar and pressing the mixture under 10 tons were obtained using Nicolet 360 and Shimadzu 8601 Fourier transform infrared (FTIR) spectrophotometers. Thermal gravimetric analyses (TGA) were performed using Shimadzu TGA-51. Zinc borate samples (10-15 mg) were loaded into an alumina pan and heated from room temperature to 600 at $10{ }^{\circ} \mathrm{C} / \mathrm{min}$ under $\mathrm{N}_{2}$ flow of $40 \mathrm{~mL} / \mathrm{min}$. $\mathrm{H}, \mathrm{C}$, and $\mathrm{N}$ content of samples were measured by using Leco CHNS-932 elemental analyzer.

\section{Results and Discussion}

The possible reactions in the production of zinc borate from borax decahydrate and zinc nitrate hexahydrate are as follows:

$$
\begin{gathered}
2 \mathrm{Na}_{2} \mathrm{~B}_{4} \mathrm{O}_{7} \cdot 10 \mathrm{H}_{2} \mathrm{O} \Leftrightarrow 4 \mathrm{Na}^{+}+\mathrm{B}_{4} \mathrm{O}_{7}^{2-}+\mathrm{HB}_{4} \mathrm{O}_{7}^{-}+ \\
\mathrm{OH}^{-}+9 \mathrm{H}_{2} \mathrm{O} \\
\mathrm{B}_{4} \mathrm{O}_{7}^{2-}+7 \mathrm{H}_{2} \mathrm{O} \rightarrow 4 \mathrm{H}_{3} \mathrm{BO}_{3}+2 \mathrm{OH}^{-} \\
\mathrm{Zn}^{2+}+4 \mathrm{OH}^{-} \Leftrightarrow \mathrm{Zn}(\mathrm{OH})_{4}^{2-}
\end{gathered}
$$$$
2 \mathrm{Zn}(\mathrm{OH})_{4}^{2-}+6 \mathrm{H}_{3} \mathrm{BO}_{3} \rightarrow 2 \mathrm{ZnO} \cdot 3 \mathrm{~B}_{2} \mathrm{O}_{3} \cdot 7 \mathrm{H}_{2} \mathrm{O}+4 \mathrm{H}_{2} \mathrm{O}+
$$$$
4 \mathrm{OH}^{-}
$$

In the production of zinc borate from borax and water-soluble zinc salt, the initial $\mathrm{pH}$ of the mixture has a significant role. While a formed product decomposes in acidic solutions, zinc oxide forms in basic mixtures. ${ }^{7}$ When borax was dissolved in water (eq 1), pH of mixture was around 9.0. The tetraborate anions produce boric acid according to eq $2 . \mathrm{Zn}^{2+}$ cations in the aqueous solution of zinc nitrate hexahydrate forms zinc tetrahydroxide anions by reacting with $\mathrm{OH}^{-}$anions (eq 3). Finally, boric acid reacts with zinc tetrahydroxide anions to produce zinc borate according to eq 4 . The $\mathrm{pH}$ of mixture at the end of reaction after filtration was measured as 6.4.

Boric acid dissolves in water as shown in eq 5. Since the boric acid is a Lewis acid, zinc oxide forms zinc hydroxide in that media according to eq 6 . Then, zinc hydroxide and boric acid reacts to zinc borate building block as shown in eq 7. Boric acid may also form other borate anions regarding the $\mathrm{pH}$ and concentration of boric acid and they may also involve in the zinc borate synthesis. Formed zinc borate specie in eq 7 turned into ultimate product releasing water as shown in eq 8 . As the reaction was carried out in the excess of boric acid, the medium was acidic at the $\mathrm{pH}$ value of 5 .

$$
\begin{gathered}
\mathrm{B}(\mathrm{OH})_{3(\mathrm{~s})} \rightarrow \mathrm{B}(\mathrm{OH})_{3(\mathrm{aq})} \\
\mathrm{ZnO}_{(\mathrm{s})}+\mathrm{H}_{2} \mathrm{O} \rightarrow \mathrm{Zn}(\mathrm{OH})_{2(\mathrm{~s})} \\
\mathrm{Zn}(\mathrm{OH})_{2(\mathrm{~s})}+3 \mathrm{~B}(\mathrm{OH})_{3(\mathrm{aq})} \rightarrow \mathrm{Zn}\left[\mathrm{B}_{3} \mathrm{O}_{3}(\mathrm{OH})_{5}\right] \cdot \mathrm{H}_{2} \mathrm{O}_{(\mathrm{s})}+2 \mathrm{H}_{2} \mathrm{O} \\
\mathrm{Zn}\left[\mathrm{B}_{3} \mathrm{O}_{3}(\mathrm{OH})_{5}\right] \cdot \mathrm{H}_{2} \mathrm{O}_{(\mathrm{s})} \rightarrow \mathrm{Zn}\left[\mathrm{B}_{3} \mathrm{O}_{4}(\mathrm{OH})_{3}\right]+2 \mathrm{H}_{2} \mathrm{O}
\end{gathered}
$$

To determine the elemental composition of zinc borate samples and the effect of supercritical $\mathrm{CO}_{2}$ drying, $\mathrm{C}, \mathrm{H}, \mathrm{N}$ contents of samples that were produced from "borax decahydrate and zinc nitrate hexahydrate, $\mathrm{ZnB}-1$ " and "boric acid and zinc oxide, ZnB-2" and supercritical $\mathrm{CO}_{2}$ dried samples were determined as shown in Table 1. Hydrogen content of zinc borate produced from borax and zinc nitrate hexahydrate ( $\mathrm{ZnB}$ 1) was found as $2.52 \%$ which is very close to the theoretical value of $2.84 \%$. Carbon and nitrogen contents of zinc borate $(\mathrm{ZnB}-1)$ are negligible and indicating that it was washed efficiently formed nitrate ions present in the reaction mixture. The presence of carbon in $\mathrm{ZnB}-1$ was not expected any way. However, it can be seen that during supercritical carbon dioxide drying due to the reaction of carbon dioxide with $\mathrm{ZnB}-1$, the carbon content of sample increased to $1.26 \%$ for $2 \mathrm{~h}$ dried sample. With the increase of drying time to 3 and $4 \mathrm{~h}$, the carbon content increased from $1.26 \%$ to values of $1.43 \%$ and $1.47 \%$, respectively. Another considerable change occurred in the $\mathrm{H}$ content of zinc borate during supercritical drying: it decreased from $2.52 \%$ to $2.22 \%$ as carbon dioxide flow caused the removal of some $\mathrm{OH}$ groups, as well. On the other hand, the hydrogen content of supercritical dried zinc borate (ZnB-2SC) obtained from boric acid and zinc oxide was found as $1.43 \%$ which corresponds to the theoretical value of $1.42 \%$. Nitrogen was not present and carbon content was not significant as expected for this sample. Conventional dried zinc borate produced from boric acid and zinc oxide was not examined in the elemental analysis.

3.1. Characterization of Supercritical $\mathrm{CO}_{2}$ Dried Zinc Borate Produced from Borax Decahydrate and Zinc Nitrate Hexahydrate. Using analytical titration method, the mole ratio of $\mathrm{B}_{2} \mathrm{O}_{3} / \mathrm{ZnO}$ was found as 1.35 (Table 1 ), which is very close to the value in theoretical formula of $2 \mathrm{ZnO} \cdot 3 \mathrm{~B}_{2} \mathrm{O}_{3}$. $7 \mathrm{H}_{2} \mathrm{O}$. FTIR spectra of zinc borates produced from borax decahydrate and zinc nitrate hexahydrate conventionally and supercritical $\mathrm{CO}_{2}$ dried for 2, 3, and $4 \mathrm{~h}$ are shown in Figure 2. The spectrum in Figure $2 \mathrm{a}$ indicates that zinc borate species has an identical spectrum with the spectrum given for 


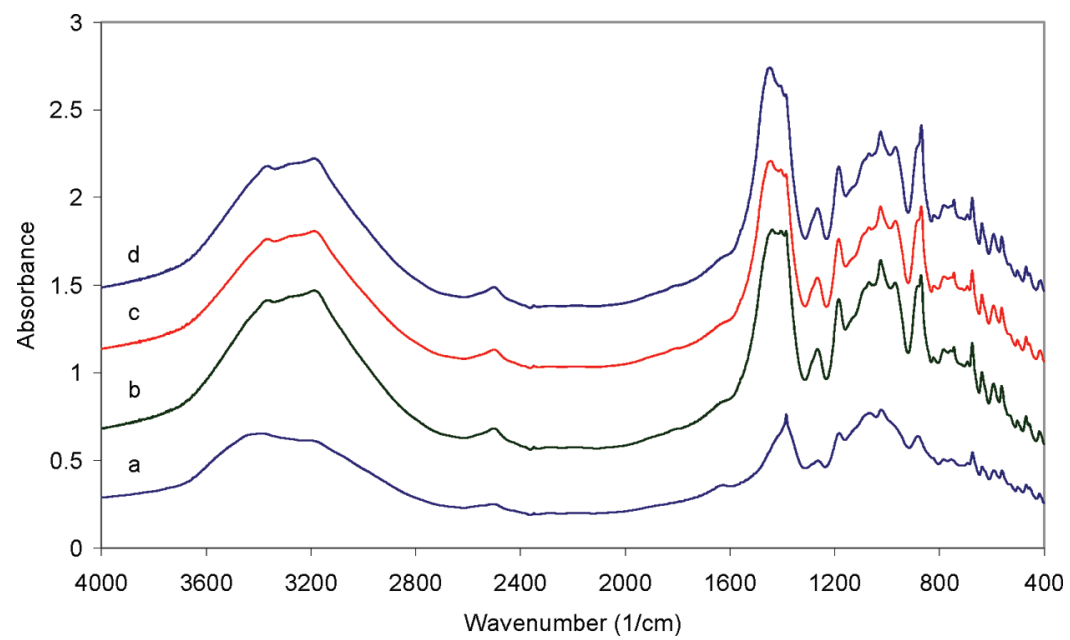

Figure 2. FTIR spectra of zinc borates dried (a) conventionally at $110{ }^{\circ} \mathrm{C}(\mathrm{ZnB}-1)$ and by $\mathrm{SC} \mathrm{CO}_{2}$ at different drying times: (b) $2 \mathrm{~h}$ (ZnB-1SC-1), (c) $3 \mathrm{~h}$ (ZnB-1SC-2), (d) 4 h (ZnB-1SC-3).

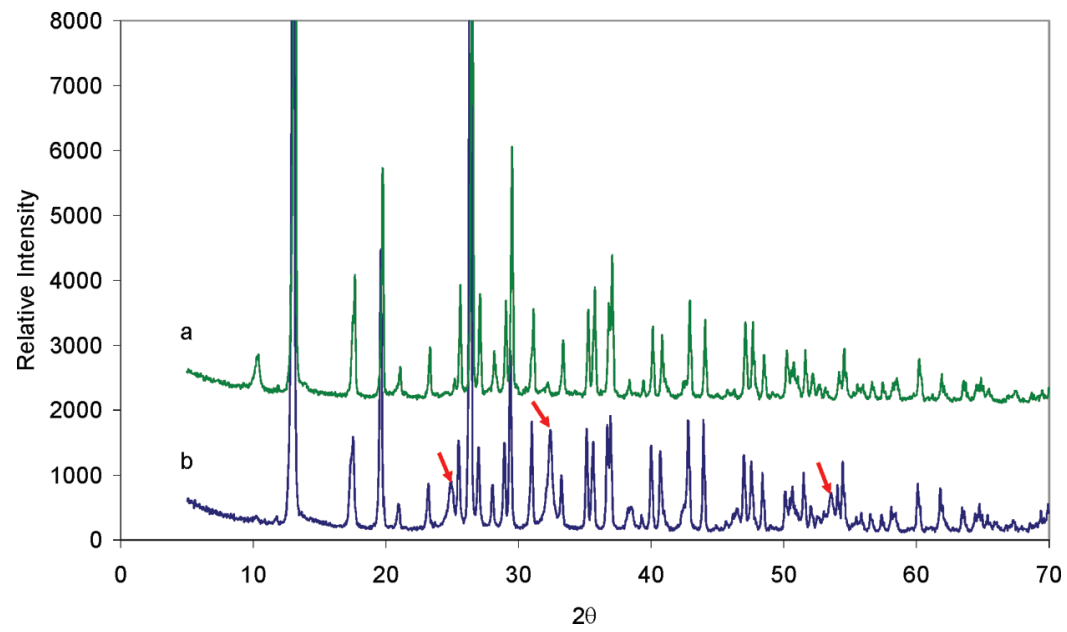

Figure 3. XRD patterns of zinc borates dried (a) conventionally at $110{ }^{\circ} \mathrm{C}(\mathrm{ZnB}-1)$ and (b) by supercritical $\mathrm{CO}_{2}$ for $4 \mathrm{~h}(\mathrm{ZnB}-1 \mathrm{SC}-3)$.

$2 \mathrm{ZnO} \cdot 3 \mathrm{~B}_{2} \mathrm{O}_{3} \cdot 7 \mathrm{H}_{2} \mathrm{O} .{ }^{17}$ The band at $1641 \mathrm{~cm}^{-1}$ is assigned to the $\mathrm{H}-\mathrm{O}-\mathrm{H}$ bending mode, which shows the compound containing the crystalline water. (Figure 2a). The other major peaks in the spectrum of zinc borate $(\mathrm{ZnB}-1)$ before and after supercritical drying are given in Table 3.

The peaks at about $1450 \mathrm{~cm}^{-1}$ (shoulder peak) and $835 \mathrm{~cm}^{-1}$ in FTIR spectra of supercritical $\mathrm{CO}_{2}$ dried zinc borate samples in Figure $2 b-d$ belong to carbonate ions. ${ }^{18}$ It was inferred from the comparison of Figure $2 \mathrm{a}$ and Figure $2 \mathrm{~b}-\mathrm{d}$ that zinc borate species ZnB-1 interacted chemically with carbon dioxide during the supercritical drying. No methanol was present in the samples since peaks related to $\mathrm{C}-\mathrm{H}$ vibrations of methanol at $2900 \mathrm{~cm}^{-1}$ were not observed in the FTIR spectra.

Figure $3 \mathrm{a}$ shows the XRD pattern of zinc borate that was produced from borax decahydrate and zinc nitrate hexahydrate (ZnB-1) and dried at $110^{\circ} \mathrm{C}$. As the major peaks at about $13.0^{\circ}$, $18.0^{\circ}, 20.0^{\circ}, 27.0^{\circ}$, and $30.0^{\circ} 2 \theta$ values are identical to the peaks of $2 \mathrm{ZnO} \cdot 3 \mathrm{~B}_{2} \mathrm{O}_{3} \cdot 7 \mathrm{H}_{2} \mathrm{O}$, it is concluded that the product is $2 \mathrm{ZnO} \cdot 3 \mathrm{~B}_{2} \mathrm{O}_{3} \cdot 7 \mathrm{H}_{2} \mathrm{O}$. Figure $3 \mathrm{~b}$ represents the XRD pattern of zinc borate that was dried by supercritical $\mathrm{CO}_{2}$. This pattern was redrawn while the intensity value was constrained to 8000 so that the small peaks can be seen easily. From the comparison of Figure $3 a$ and Figure $3 b$, it can be deducted that there are extra peaks in the XRD pattern of supercritical $\mathrm{CO}_{2}$ dried zinc borate. The peaks at $2 \theta$ values of $24.96^{\circ}, 32.45^{\circ}$, and $53.67^{\circ}$, indicated by arrows, belong to zinc carbonate crystal structure. ${ }^{18}$
During the supercritical $\mathrm{CO}_{2}$ drying under $10 \mathrm{MPa}$ and $40{ }^{\circ} \mathrm{C}$, zinc borate reacted with $\mathrm{CO}_{2}$ to produce zinc carbonate. The formation of zinc carbonate during drying was also supported by FTIR analysis.

SEM photographs of zinc borate and supercritical $\mathrm{CO}_{2}$-dried zinc borate samples are shown in Figure $4 a-d$. Figure 4a clearly shows that there are two types of particles; the first type is micrometer-sized prismatic rods and the second kind is nanosized flakes. By comparison of the SEM image of Figure $4 \mathrm{a}$ with that of Figure $4 d$, it can be seen that reaction started on the surface of the micrometer-sized particles and the amount of zinc borate reacted with $\mathrm{CO}_{2}$ on the surface has increased with increasing drying time. The particle size of spherical particles on the surface of zinc borate varies between 200 and $500 \mathrm{~nm}$.

TGA curves of zinc borate samples produced from borax decahydrate and zinc nitrate hexahydrate and supercritical $\mathrm{CO}_{2}$ dried samples are given in Figure 5. In these thermograms, the first step starts at around $180{ }^{\circ} \mathrm{C},(T 1)$, and it represents the removal of water from the structure by evaporation of crystallization water and water formed by condensation of $\mathrm{OH}$ groups. The second step which occurs at around $370{ }^{\circ} \mathrm{C},(T 2)$, is due to the removal of $\mathrm{CO}_{2}$ from zinc carbonate structure. Conventionally dried zinc borate at $110{ }^{\circ} \mathrm{C}$ begins to lose its hydration water at $180{ }^{\circ} \mathrm{C}$ with a mass loss of $23.0 \%$ (Figure 5a) which is close to the theoretical value $25.32 \%$ calculated from the 


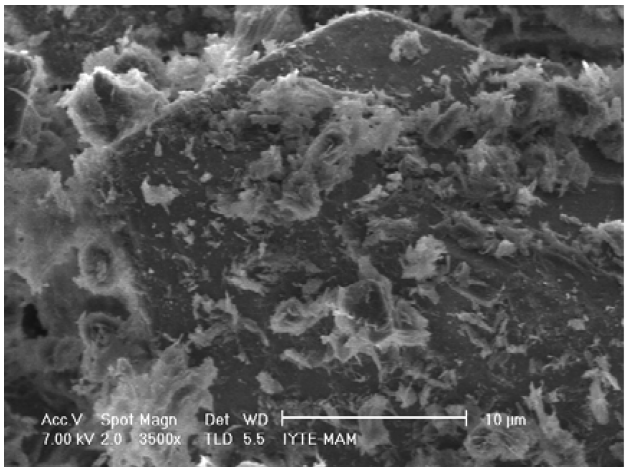

(a)

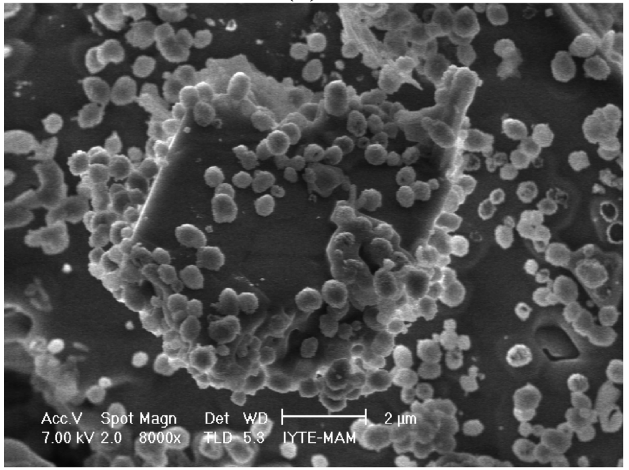

(c)

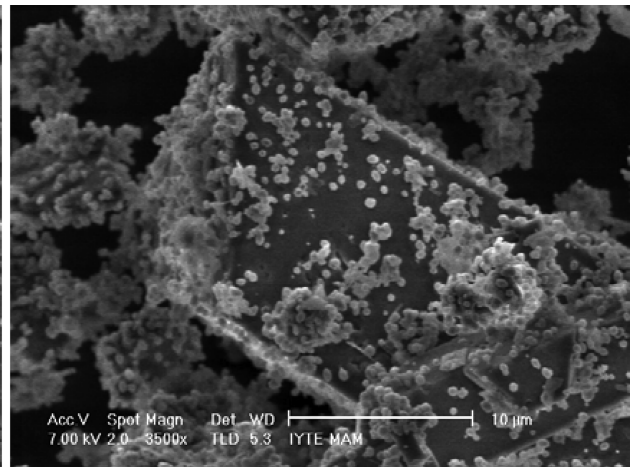

(b)

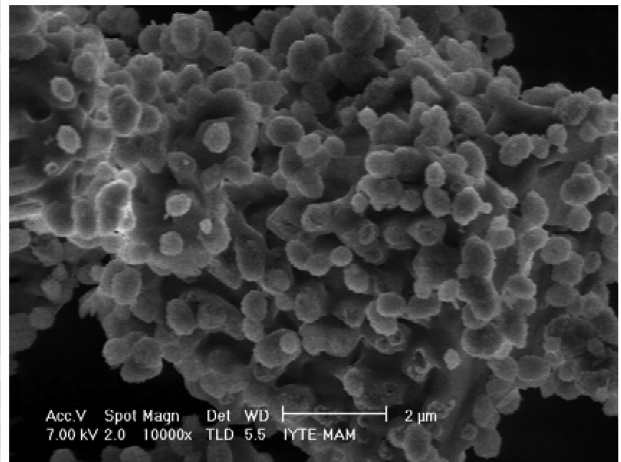

(d)

Figure 4. SEM microphotographs of zinc borates dried (a) conventionally at $110{ }^{\circ} \mathrm{C}(\mathrm{ZnB}-1)$ and by $\mathrm{SC} \mathrm{CO}_{2}$ at different drying times: (b) $2 \mathrm{~h}$ (ZnB-1SC-1), (c) $3 \mathrm{~h}$ (ZnB-1SC-2), (d) 4 h (ZnB-1SC-3).

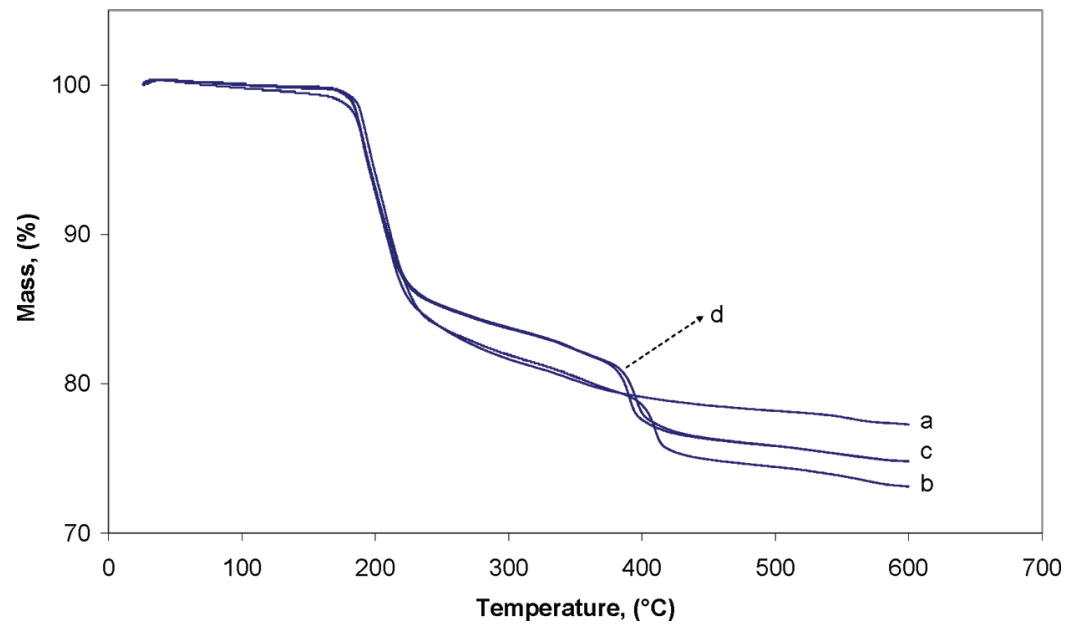

Figure 5. TGA curves of zinc borates dried (a) conventionally at $110{ }^{\circ} \mathrm{C}(\mathrm{ZnB}-1)$ and by $\mathrm{SC} \mathrm{CO}_{2}$ at different drying times: (b) $2 \mathrm{~h}$ (ZnB-1SC-1), (c) $3 \mathrm{~h}$ (ZnB-1SC-2), (d) 4 h (ZnB-1SC-3).

formula of $2 \mathrm{ZnO} \cdot 3 \mathrm{~B}_{2} \mathrm{O}_{3} \cdot 7 \mathrm{H}_{2} \mathrm{O}$. On the other hand, zinc borates dried by supercritical $\mathrm{CO}_{2}$ under $10 \mathrm{MPa}$ and $40{ }^{\circ} \mathrm{C}$ for drying time of $2-4 \mathrm{~h}$ show two steps in the TGA curves (Figure $5 \mathrm{~b}-\mathrm{d}$ ). The first step that started at $180{ }^{\circ} \mathrm{C}$ with a mass loss of $16.88 \%$ belongs to the water loss of zinc borate, and the second step that occurred at $370{ }^{\circ} \mathrm{C}$ with a mass loss of $4.78 \%$ (ZnB-1SC1) pertains to the decomposition of zinc carbonate. ${ }^{19}$ After supercritical $\mathrm{CO}_{2}$ drying, the approximate composition of the ultimate product is zinc borate (85\%) and zinc carbonate (15\%) as calculated from the $\mathrm{CO}_{2}$ weight loss. $\mathrm{CO}_{2} \%$ found from $\mathrm{C}$ content and TGA and $\mathrm{H}_{2} \mathrm{O} \%$ from $\mathrm{H}$ content and TGA were very close to each other as reported in Table 1 . The thermal stability properties of zinc borates and samples that were dried by supercritical $\mathrm{CO}_{2}$ are summarized in Table 2. The $\mathrm{CO}_{2}$ content of ZnB-1SC1, ZnB-1SC2, and ZnB-1SC-3 samples was
Table 2. Thermal Behavior of Zinc Borate Samples

\begin{tabular}{lcccc}
\hline \multicolumn{1}{c}{ sample } & $\mathrm{T} 1\left({ }^{\circ} \mathrm{C}\right)$ & $\mathrm{H}_{2} \mathrm{O}$ loss $\%$ & $\mathrm{~T} 2\left({ }^{\circ} \mathrm{C}\right)$ & $\mathrm{CO}_{2}$ loss $\%$ \\
\hline ZnB-1 & 180 & 23.01 & & \\
ZnB-1SC-1 & 180 & 16.88 & 386 & 4.78 \\
ZnB-1SC-2 & 180 & 15.35 & 370 & 5.50 \\
ZnB-1SC-3 & 180 & 15.27 & 370 & 5.76 \\
ZnB-2 & 291 & 13.31 & & \\
ZnB-2SC & 303 & 13.16 & &
\end{tabular}

determined by TGA as $4.78 \%, 5.50 \%$, and $5.76 \%$, respectively (Table 2). They contained $13.87-16.41 \%$ (wt) $\mathrm{ZnCO}_{3}$ as listed in Table 1.

3.2. Characterization of Supercritical $\mathrm{CO}_{2}$ Dried Zinc Borate Produced from Boric Acid and Zinc Oxide. The zinc borate (ZnB-2) prepared from boric acid and zinc oxide at 90 ${ }^{\circ} \mathrm{C}$ for $5 \mathrm{~h}$ reaction time is a zinc borate species with the oxide 


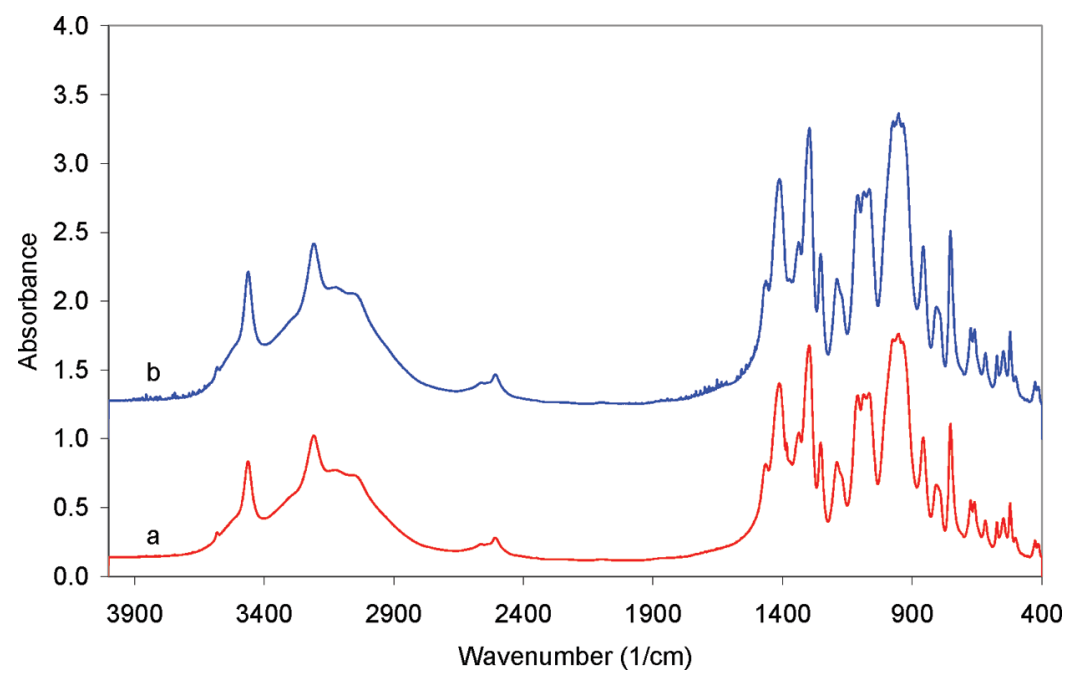

Figure 6. FTIR spectra of zinc borates dried (a) by $\mathrm{SC} \mathrm{CO}_{2}$ for $2 \mathrm{~h}(\mathrm{ZnB}-2 \mathrm{SC})$ and (b) by conventional means at $110{ }^{\circ} \mathrm{C}(\mathrm{ZnB}-2)$.

Table 3. Observed Wavenumbers $\left(\mathrm{cm}^{-1}\right)$ in FTIR Spectra for Zinc Borate Samples

\begin{tabular}{|c|c|c|c|}
\hline \multicolumn{2}{|c|}{ from borax decahydrate and zinc nitrate hexahydrate (ZnB-1) } & \multirow{2}{*}{$\begin{array}{l}\text { from zinc oxide and boric acid; before and } \\
\text { after supercritical extraction ( } \mathrm{ZnB}-2)\end{array}$} & \multirow[b]{2}{*}{ assignment } \\
\hline before supercritical $\mathrm{CO}_{2}$ extraction & $\overline{\text { after supercritical } \mathrm{CO}_{2} \text { extraction }}$ & & \\
\hline 3417 & 3417 & 3471 & $v(\mathrm{O}-\mathrm{H})$ \\
\hline 2515 & 2515 & 2520 & \\
\hline \multirow[t]{2}{*}{1641} & 1641 & & $\delta(\mathrm{H}-\mathrm{O}-\mathrm{H})$ \\
\hline & 1450 & & $\mathrm{CO}_{3}^{-2}$ \\
\hline 1384 & 1384 & 1425 & $v_{\mathrm{as}}\left(\mathrm{B}_{3}-\mathrm{O}\right)$ \\
\hline 1274 & 1274 & 1257 & $\delta(\mathrm{B}-\mathrm{O}-\mathrm{H})$ \\
\hline 1188 & 1188 & 1200 & $v_{\text {as }}\left(\mathrm{B}_{4}-\mathrm{O}\right)$ \\
\hline 1078 & 1078 & 1118 & \\
\hline 1028 & 1028 & & \\
\hline- & 970 & & $\mathrm{CO}_{3}^{-2}$ \\
\hline \multirow[t]{2}{*}{889} & 889 & 960 & $v_{\mathrm{s}}\left(\mathrm{B}_{3}-\mathrm{O}\right)$ \\
\hline & & 864 & \\
\hline 596 & 596 & 553 & $\delta\left(\mathrm{B}_{3}-\mathrm{O}\right), \delta\left(\mathrm{B}_{4}-\mathrm{O}\right)$ \\
\hline 563 & 563 & 526 & \\
\hline 472 & 472 & 432 & $\delta\left(\mathrm{B}_{4}-\mathrm{O}\right)$ \\
\hline 420 & 420 & & \\
\hline
\end{tabular}

formula of $2 \mathrm{ZnO} \cdot 3 \mathrm{~B}_{2} \mathrm{O}_{3} \cdot 3 \mathrm{H}_{2} \mathrm{O}$. The mole ratio of $\mathrm{B}_{2} \mathrm{O}_{3} / \mathrm{ZnO}$ was determined as 1.50 from analytical titration, and water content was determined by thermal gravimetric analysis as $13.31 \%$ (Table 2) that corresponds to its theoretical value of $12.69 \%$. The FTIR spectrum of the conventionally dried compound (Figure 6b) shows some important properties of $2 \mathrm{ZnO} \cdot 3 \mathrm{~B}_{2} \mathrm{O}_{3} \cdot 3 \mathrm{H}_{2} \mathrm{O}$. All hydrated borate salts have a broad peak at $2200-3600 \mathrm{~cm}^{-120}$ resulting from stretching vibrations of $\mathrm{OH}$ groups in their structure; $2 \mathrm{ZnO} \cdot 3 \mathrm{~B}_{2} \mathrm{O}_{3} \cdot 3 \mathrm{H}_{2} \mathrm{O}$ has two major sharp peaks at 3210 and $3470 \mathrm{~cm}^{-1}$ in this region which is accepted as characteristics of this type. ${ }^{21}$ Another important feature of this product is that it does not have crystallization water in its structure since it does not have a peak at $1635 \mathrm{~cm}^{-1}$ belonging to bending vibrations of $\mathrm{H}_{2} \mathrm{O}$ molecules in its IR spectrum. The chemical structure of zinc borate of this type has been recently updated by Schubert and his co-workers as $\left(\mathrm{Zn}\left[\mathrm{B}_{3} \mathrm{O}_{4}(\mathrm{OH})_{3}\right]\right)$ which has a polymeric network structure. ${ }^{1}$ Figure 6 a shows the FTIR spectrum of zinc borate that was dried by supercritical $\mathrm{CO}_{2}$ for $2 \mathrm{~h}$. It can be inferred that there is no change in the chemical structure of zinc borate during supercritical drying. Conventionally dried and supercritical $\mathrm{CO}_{2}$ dried zinc borate $\left(2 \mathrm{ZnO} \cdot 3 \mathrm{~B}_{2} \mathrm{O}_{3} \cdot 3 \mathrm{H}_{2} \mathrm{O}\right)$ samples had identical spectra in which major peaks were summarized in Table 3.

$\mathrm{X}$-ray diffraction patterns of zinc borate samples dried by supercritical $\mathrm{CO}_{2}$ and conventionally at $110{ }^{\circ} \mathrm{C}$ are given in Figure $7 \mathrm{a}$ and Figure $7 \mathrm{~b}$, respectively. This zinc borate specie has a crystal structure that is identical to that of $2 \mathrm{ZnO}$. $3 \mathrm{~B}_{2} \mathrm{O}_{3} \cdot 3 \mathrm{H}_{2} \mathrm{O}$. ${ }^{16}$ The most important characteristic of this zinc borate species is that the major peaks begin to occur at $18.0^{\circ}$ $2 \theta$ value, and other important peaks in the XRD pattern are observed at about $20.0^{\circ}, 22.0^{\circ}, 24^{\circ}, 26^{\circ}, 29^{\circ}, 30^{\circ}$ and $36^{\circ} 2 \theta$ values. It can be concluded from the comparison of Figure $7 \mathrm{a}$ and Figure $7 \mathrm{~b}$ that there is no change in the crystal structure of zinc borate after supercritical $\mathrm{CO}_{2}$ drying.

From SEM micrographs of conventionally dried particles (Figure 8a), particle size was determined about $2 \mu \mathrm{m}$. Particles stick to each other and supercritical $\mathrm{CO}_{2}$ has no influence on separation of these particles (Figure 8b). Particles in both Figure $8 \mathrm{a}$ and Figure $8 \mathrm{~b}$ have smooth surfaces and random shapes.

To determine the water content of zinc borate and the supercritical $\mathrm{CO}_{2}$ drying effect, samples were analyzed by TGA. Figure 9 shows the TGA plots of zinc borates dried convention- 


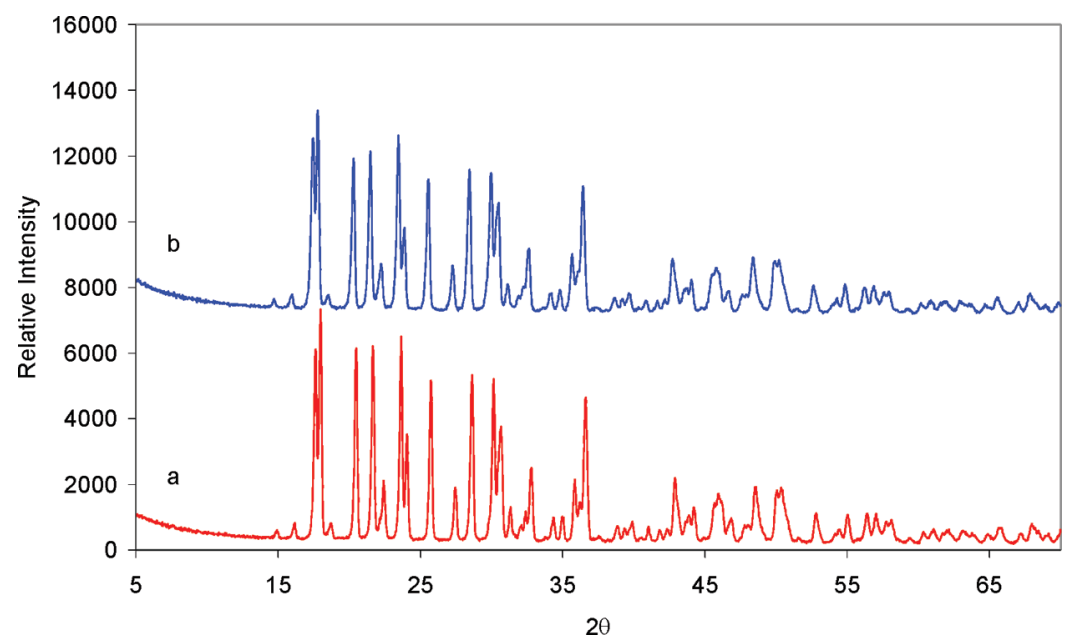

Figure 7. XRD diagrams of zinc borates dried (a) by $\mathrm{SC} \mathrm{CO}_{2}$ for $2 \mathrm{~h}(\mathrm{ZnB}-2 \mathrm{SC})$ and (b) by conventional means at $110{ }^{\circ} \mathrm{C}(\mathrm{ZnB}-2)$.

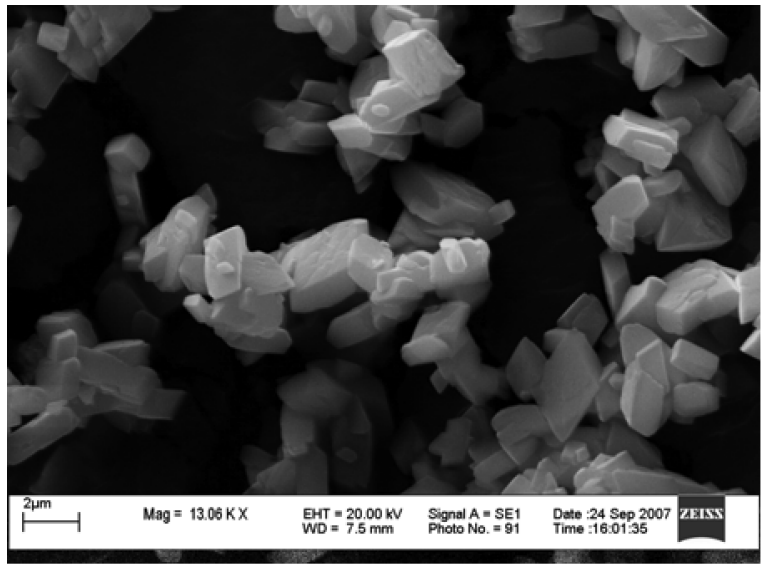

(a)

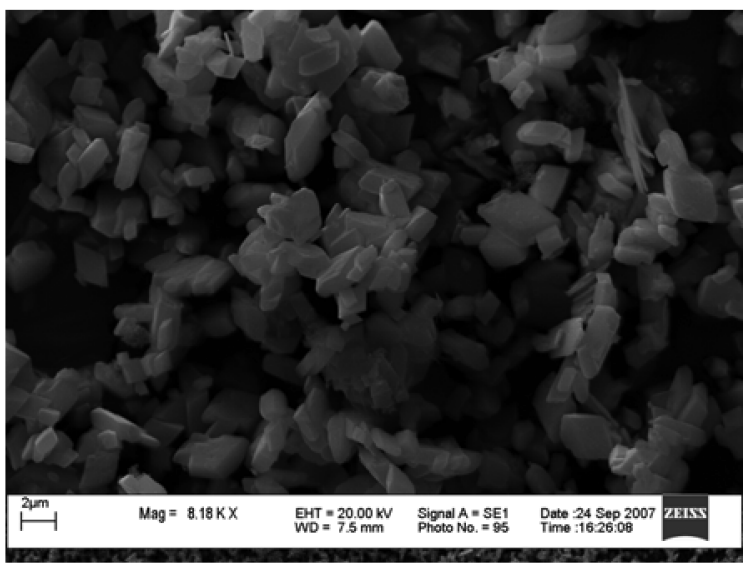

(b)

Figure 8. SEM microphotographs of zinc borates dried (a) conventionally at $110{ }^{\circ} \mathrm{C}(\mathrm{ZnB}-2)$ and (b) by $\mathrm{SC} \mathrm{CO}_{2}(\mathrm{ZnB}-2 \mathrm{SC})$.

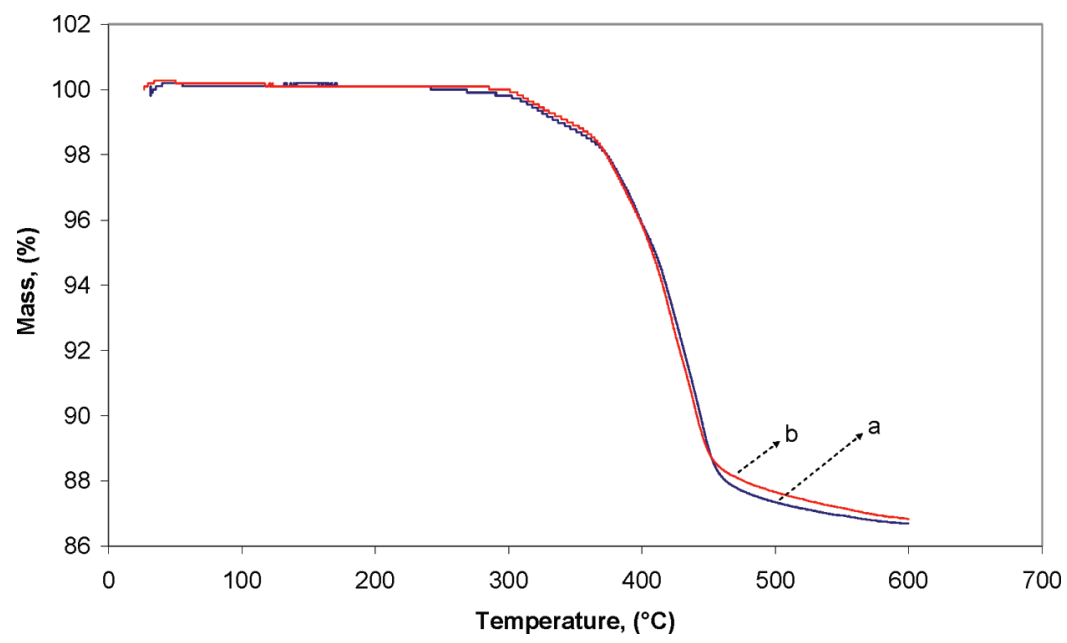

Figure 9. TGA curves of zinc borates dried (a) conventionally at $110{ }^{\circ} \mathrm{C}(\mathrm{ZnB}-2)$ and (b) by $\mathrm{SC} \mathrm{CO}_{2}$ for $2 \mathrm{~h}(\mathrm{ZnB}-2 \mathrm{SC})$.

ally at $110{ }^{\circ} \mathrm{C}$ and by supercritical $\mathrm{CO}_{2}$. Conventional dried zinc borate (ZnB-2) started to lose weight at $290{ }^{\circ} \mathrm{C}$; supercritical $\mathrm{CO}_{2}$ dried zinc borate began to lose weight at $303{ }^{\circ} \mathrm{C}$ as shown in Table 2. The total weight loss of both samples was about $13.0 \%$ which is very close to theoretical value of $12.69 \%$ for $2 \mathrm{ZnO} \cdot 3 \mathrm{~B}_{2} \mathrm{O}_{3} \cdot 3 \mathrm{H}_{2} \mathrm{O}$ until $600{ }^{\circ} \mathrm{C}$. The water content was also determined as $12.81 \%$ from elemental $\mathrm{H}$ content of a supercritically dried sample.
It can be concluded that $\mathrm{ZnB}-2$ was not affected chemically by supercritical carbon dioxide drying.

Carbon Dioxide and Zinc Borate Interaction. It was anticipated that carbonic acid was formed from the dissolution of carbon dioxide in water that was released from the zinc borate structure under supercritical conditions as shown in eq 9. Then, zinc borate-methanol mixture reacted with carbonic acid as shown in eq 10 . 


$$
\begin{aligned}
& \mathrm{Zn}\left[\mathrm{B}_{3} \mathrm{O}_{3}(\mathrm{OH})_{5}\right] \cdot \mathrm{H}_{2} \mathrm{O}_{(\mathrm{s})}+\mathrm{CO}_{2(\mathrm{~g})} \rightarrow \mathrm{Zn}\left[\mathrm{B}_{3} \mathrm{O}_{3}(\mathrm{OH})_{5}\right]_{(\mathrm{s})}+ \\
& \mathrm{H}_{2} \mathrm{CO}_{3(\mathrm{aq})}
\end{aligned}
$$

$\mathrm{Zn}\left[\mathrm{B}_{3} \mathrm{O}_{3}(\mathrm{OH})_{5}\right]_{(\mathrm{s})}+2 \mathrm{H}^{+}+\left(\mathrm{CO}_{3}\right)_{(\mathrm{aq})}^{-2} \rightarrow \mathrm{ZnCO}_{3(\mathrm{~s})}+$

$$
\left[\mathrm{B}_{3} \mathrm{O}_{3}(\mathrm{OH})_{3}\right]_{(\mathrm{s})}+2 \mathrm{H}_{2} \mathrm{O}
$$

Since the structure of $\mathrm{Zn}\left[\mathrm{B}_{3} \mathrm{O}_{4}(\mathrm{OH})_{3}\right]$ is quite stable and has no water of crystallization, no carbonate formation was observed in the drying of that zinc borate. The larger particle size of that product might be another reason for not observing any reaction, since the reaction between zinc borate and carbon dioxide takes places on the surface of the solid particles. In this study, the particle size of $\mathrm{Zn}\left[\mathrm{B}_{3} \mathrm{O}_{4}(\mathrm{OH})_{3}\right]$ and $\mathrm{Zn}\left[\mathrm{B}_{3} \mathrm{O}_{3}(\mathrm{OH})_{5}\right] \cdot \mathrm{H}_{2} \mathrm{O}$ that reacted were $2 \mu \mathrm{m}$ and $200-500 \mathrm{~nm}$, respectively.

\section{Conclusion}

Zinc borate species having different properties had different application fields depending on economics and final end use. $2 \mathrm{ZnO} \cdot 3 \mathrm{~B}_{2} \mathrm{O}_{3} \cdot 7 \mathrm{H}_{2} \mathrm{O}$ obtained from borax decahydrate and zinc nitrate hexahydrate has structure of $\mathrm{Zn}\left[\mathrm{B}_{3} \mathrm{O}_{3}(\mathrm{OH})_{5}\right] \cdot \mathrm{H}_{2} \mathrm{O}$ that comprises both water of crystallization and bound water as $\mathrm{OH}$ groups attached to main unit. However, $2 \mathrm{ZnO} \cdot 3 \mathrm{~B}_{2} \mathrm{O}_{3} \cdot 3 \mathrm{H}_{2} \mathrm{O}$ obtained from boric acid and zinc oxide has the structure of $\left(\mathrm{Zn}\left[\mathrm{B}_{3} \mathrm{O}_{4}(\mathrm{OH})_{3}\right]\right)$, which has no water of crystallization. Water of crystallization is more labile and reactive than bound $\mathrm{OH}$ groups. While zinc borate having water of crystallization in its structure reacted partially with $\mathrm{CO}_{2}$ to produce zinc carbonate, zinc borate without water of crystallization did not react with $\mathrm{CO}_{2}$ under supercritical drying conditions. The presence of nanosized spherical particles on the zinc borate surface made the surface reaction detectable in the time period of drying for $\mathrm{Zn}\left[\mathrm{B}_{3} \mathrm{O}_{3}(\mathrm{OH})_{5}\right] \cdot \mathrm{H}_{2} \mathrm{O}$. The final product contained about $15 \%$ zinc carbonate. Even if no interaction of carbon dioxide with zinc borate was expected based on previous publications on magnesium borate and copper borate, interactions were observed in this study for $\mathrm{Zn}\left[\mathrm{B}_{3} \mathrm{O}_{3}(\mathrm{OH})_{5}\right] \cdot \mathrm{H}_{2} \mathrm{O}$. Since no interaction was observed for $2 \mu \mathrm{m}$ sized $2 \mathrm{ZnO} \cdot 3 \mathrm{~B}_{2} \mathrm{O}_{3} \cdot 3 \mathrm{H}_{2} \mathrm{O}$ particles in the present study, further studies are being made on synthesis of nanoparticles of $2 \mathrm{ZnO} \cdot 3 \mathrm{~B}_{2} \mathrm{O}_{3} \cdot 3 \mathrm{H}_{2} \mathrm{O}$ and their drying with supercritical carbon dioxide.

\section{Acknowledgment}

The authors acknowledge the financial support from The Scientific and Technical Research Council of Turkey (TÜBİTAK) (project number: 105M358) and TÜBITTAK scholarship for study in Prof. Ram B. Gupta's laboratory.

\section{Literature Cited}

(1) Schubert, D. M.; Alam, F.; Visi, M. Z.; Knobler, C. B. Structural characterization and chemistry of industrially important zinc borate $\mathrm{Zn}\left[\mathrm{B}_{3} \mathrm{O}_{4}(\mathrm{OH})_{3}\right]$. Chem. Mater. 2003, 15, 866-871.
(2) Shen, K. K.; Kochesfahani, S.; Jouffret, F. Review article: Zinc borates as multifunctional polymer additives. Polym. Adv. Technol. 2008, 19, 469-474.

(3) Erdoğdu, C. A.; Atakul, S.; Balköse, D.; Ülkü, S. Development of synergistic heat stabilizers for pvc from zinc borate-zinc phosphate. Chem. Eng. Commun. 2009, 196, 148-160.

(4) Schubert, D. M. Zinc Borate. U.S. Patent 5,472,644, December 5, 1995.

(5) Kirk-Othmer Encyclopedia of Chemical Technology, 4th ed.; John, Wiley and Sons: New York, 1994; Vols 10, 4.

(6) Shi, X.; Xiao, Y.; Li, M.; Yuang, L.; Sun, J. Synthesis of an industrially important zinc borate, $2 \mathrm{ZnO} \cdot 3 \mathrm{~B}_{2} \mathrm{O}_{3} \cdot 3 \mathrm{H}_{2} \mathrm{O}$, by a rheological phase reaction method. Powder Technol. 2008, 186, 263-266.

(7) Shi, X.; Yuan, L.; Sun, X.; Chang, C.; Sun, J. Controllable synthesis of $4 \mathrm{ZnO} \cdot \mathrm{B}_{2} \mathrm{O}_{3} \cdot \mathrm{H}_{2} \mathrm{O}$ nano-/microstructures with different morphologies: Influence of hydrothermal reaction parameters and formation mechanism. J. Phys. Chem. C. 2008, 112, 3558-3567.

(8) Tian, Y.; He, Y.; Yu, L.; Deng, Y.; Zheng, Y.; Sun, F.; Liu, Z.; Wang, Z. In situ and one-step synthesis of hydrophobic zinc borate nanoplalets. Colloids Surf., A 2008, 312, 99-103.

(9) Tian, Y.; Guo, Y.; Jiang, M.; Sheng, Y.; Hari, B.; Zhang, G.; Jiang, Y.; Zhou, B.; Zhu, Y.; Wang, Z. Synthesis of hydrophobic zinc borate nanodiscs for lubrication. Mater. Lett. 2006, 60, 2511-2515.

(10) Brinker, C. J.; Scherer, G. W. Sol-Gel Science: The Physics and Chemistry of Sol-Gel Processing. Academic Press Inc: San Diego, 1990; pp 501-509.

(11) Perrut, M. Supercritical fluid applications: industrial developments and economic issues. Ind. Eng. Chem. Res. 2000, 39, 4531-4535.

(12) O'Neil, A.; Watkins, J. J. Fabrication of device nanostructures using supercritical fluids. MRS Bull. 2005, 30, 967-975.

(13) Dong, J. X.; Hu, Z. S. A study of the anti-wear and friction-reducing properties of the lubricant additive, nanometer zinc borate. Tribol. Int. 1998, 31, 219-222.

(14) Hu, Z. S.; Lai, R.; Lou, F.; Wang, L. G.; Chen, Z. L.; Chen, G. X.; Dong, J. X. Preparation and tribological properties of nanometer magnesium borate as lubricating oil additive. Wear 2002, 252, 370-374.

(15) Hu, Z. S.; Dong, J. X.; Chen, G. X.; Lou, F. Preparation of nanometer copper borate with supercritical carbondioxide drying. Powder Technol. 1999, 102, 171-176.

(16) Sawada, H.; Igarashi, H.; Sakao, K. Zinc Borate and Production Method and Use Thereof. U. S. Patent. 6,780,913 B2, August 24, 2004.

(17) Gao, Y. H.; Liu, Z. H. Synthesis and thermochemistry of two zinc borates, $\mathrm{Zn}_{2} \mathrm{~B}_{6} \mathrm{O}_{11} \cdot 7 \mathrm{H}_{2} \mathrm{O}$ and $\mathrm{Zn}_{3} \mathrm{~B}_{10} \mathrm{O}_{18} \cdot 14 \mathrm{H}_{2} \mathrm{O}$. Thermochim. Acta 2009, 484, 27-31.

(18) Kanari, N.; Mishra, D.; Gaballah, I.; Dupré, B. Thermal decomposition of zinc carbonate hydroxide. Thermochim. Acta 2004, 410, 93-100.

(19) Wu, W.; Jiang, Q. Preparation of nanocrystalline zinc carbonate and zinc oxide via solid-state reaction at room temperature. Mater. Lett. 2006, 60, 2791-2794.

(20) Jun, L.; Shupping, X.; Shiyang, G. FT-IR and Raman Spectroscopic Study of Hydrated Borates. Spectrochim. Acta 1995, 51A-4, 519-532.

(21) Eltepe, H. E.; Balköse, D.; Ülkü, S. Effect of Temperature and Time on Zinc Borate Species Formed from Zinc Oxide and Boric Acid in Aqueous Medium. Ind. Eng. Chem. Res. 2007, 46-8, 2367-2371.

Received for review February 23, 2009 Revised manuscript received April 24, 2009 Accepted May 8, 2009

IE9003046 